\title{
Overcapitalization and social norms of cooperation in a small-scale fishery
}

\author{
Robbert Schaap* Andries Richter ${ }^{\dagger \ddagger}$
}

August 13, 2019

\begin{abstract}
The increasing technological efficiency of harvesting equipment has been identified as one of the main causes of overcapacity and overexploitation of natural resources. In this paper, a formal model is developed which studies the effects of technological efficiency as an endogenous variable within a bioeconomic system. We model capital investments in a fishery, where investment decisions are made less frequently than the allocation of variable inputs. We study how the possibility to invest in capital affects open access dynamics, and also the evolution of cooperative harvesting norms. We find that the possibility to make large capital investments can destabilize cooperation, especially if enforcement capacity is low. Further, we find that communities can preserve cooperation by agreeing on a resource level that is lower than socially-optimal. This reduces the incentive to deviate from the cooperative strategy and invest in capital.
\end{abstract}

5

Keywords: Social-Ecological Systems, Cooperation, Investment, Social Norms, Technological Efficiency, Fisheries, Overcapacity, Evolutionary Game Theory.

Acknowledgements: We are grateful to Florian Diekert and Linda Nøstbakken, as well as participants from EAERE 2017, and the World Conference on Natural Resource Modeling 2017 for valuable comments. The authors gratefully acknowledge funding from the Norwegian Research Council under the Marinforsk programme through the project Fishtech (Project Number: 280541)(A.R.) and the European Commission through the project NATCOOP (ERC StGr. 678049) (R.S.).

Author contributions: RS designed the research and developed the model with input from AR. All authors contributed to the analysis and writing of the final manuscript.

\section{Introduction}

Globally, overexploitation of marine resources remains a major societal problem (Costello et al. 2016; Melnychuk et al., 2017). A common property regime, crafted by local communities has been shown to have the potential to successfully govern marine resources,

\footnotetext{
${ }^{*}$ Research Center for Environmental Economics, Department of Economics, Heidelberg University

${ }^{\dagger}$ Environmental Economics and Natural Resources group, Sub-Department of Economics, Wageningen University, The Netherlands

${ }^{\ddagger}$ Centre for Ecological and Evolutionary Synthesis (CEES), Department of Biosciences, University of Oslo, Norway
} 
especially if formal regulations are infeasible (Gutierrez et al., 2011, Ostrom, 1990). In such a setting, social norms can be a powerful mechanism to enforce sustainable harvesting strategies (Ostrom, 2009, Lubchenco et al., 2016; Nyborg et al., 2016). At the same time, social norms can be fragile, especially if individual agents can take advantage of cooperative efforts by others and are tempted to over-harvest (Richter et al., 2013). A key factor determining the ability to over-harvest are investments in fishing vessels, gear, and other equipment (Hilborn et al., 2003; Worm et al., 2009).

In this paper, we analyze whether social norms of cooperation can successfully regulate 40 investment in fishing capacity. We develop a theoretical model that features a small community having access to a common pool resource. Main novelty of the model is that harvesting efficiency is not constant, but dependent on the amount of capital that each agent has accumulated. Essentially, each agent decides on the amount of (i) short term inputs and (ii) long term capital to be invested in a fishery. We assume that the use of all

45 variable inputs (e.g. fuel, labor) that determines fishing intensity for a given capital stock is allocated frequently (potentially daily) and is therefore the faster changing variable. The decision how much to spend on maintaining or upgrading equipment is based on the expected net return from the investment, and will be the slower changing variable. This creates a dynamic system in which the allocation of variable inputs becomes a function of the capital stock. This implies that variable inputs are chosen optimally based on the state of the resource and the amount of capital an agent has accumulated. Such fast-slow dynamics add realism, while preserving analytical tractability.

We analyze how the ability to invest in harvesting capacity affects cooperative resource exploitation based on social norms. We follow the seminal evolutionary game theory

55 framework by Sethi and Somanathan (1996), in which cooperative harvesting norms are enforced through punishment. Agents act either cooperatively and harvest the resource sustainably or act selfishly and maximize their individual gains by building up capital stocks that are larger than collectively optimal. Agents will stop cooperating if it offers a higher utility to do so. The framework is therefore consistent with the principle of the 60 "rational criminal" which states that a risk neutral individual would commit an illegal act when the expected benefit from that illegal act is higher than the expected cost (Becker, 1968).

Understanding how capital investments affect the fate of a fishery is relevant for several reasons. The increasing efficiency of fishing vessels creates multiple complications in fisheries management, as it can affect stock assessments (Maunder et al., 2006; Eigaard et al., 2014), generate or sustain overcapacity (Villasante and Sumaila, 2010: Clark, 2006; Eigaard et al., 2014), and create incentives for illegal fisheries (Agnew et al., 2009; Gallic and Cox, 2006). While the bulk of literature assumes efficiency - usually expressed as catchability - to be exogenous, we specifically take into account that efficiency is endogenous and dependent on investment. Investments may include new or larger vessels, fish finding equipment, improved gear designs and more powerful engines. All of those may have a positive effect on catchability and therefore lower the per unit harvesting costs (Squires and Vestergaard, 2013). The introduction of such innovations is primarily an investment decision, where the cost of the investment has to be earned back over the 75 lifetime of the investment (Whitmarsh, 1990). However, the increase in efficiency will - if unregulated - increase the capacity of the fishery and the pressure that is exerted on the fish stock (Eigaard et al., 2014).

We make two contributions to the literature. First, we formalize endogenous capital in a fisheries model taking into account that capital is revised less frequently than effort. 80 While the observation that certain factors of production - such as capital - are fixed in 
the short run is common in microeconomic modeling (Varian, 1992), and also reflected in many empirical fisheries models (e.g. Huang and Smith (2014)), formalizing such dynamics is a novel contribution in the field of fisheries 11 Second, we add to the literature on the evolution of social norms for common pool resource harvesting. While many papers have looked at different mechanisms that may stabilize cooperation, such as punishment (Sethi and Somanathan, 1996; Noailly et al., 2003), ostracism (Tavoni et al., 2012), moral persuasion (Richter et al., 2013), identity considerations (Bulte and Horan, 2010), conditional cooperation (Richter and Grasman, 2013), or spatial structure (Noailly et al., 2007), the focus of this paper is to what extent social norms can regulate the investment of capital in a fishery. In particular, we take into consideration how cooperation can be stabilized in such case.

In Sethi and Somanathan (1996), a community either features full cooperation or defection, depending on specific parameters, such as punishment strength and technological efficiency. If efficiency were to increase, cooperation would simply break down at a certain point. An open question remains how the community may be able to actively preserve social norms of cooperation. We show that the size of the resource stock is a potential device through which the community may stabilize cooperation. If the community aims for a lower than socially optimal resource stock, cooperation is maintained. So a second-best solution actually stabilizes cooperation if a first best is not available. This mechanism is akin to the "modesty may pay" principle in coalition theory reflecting that international environmental agreements may be stable if targets are not too ambitious (Finus and Maus, 2008). The idea is also reflected in Copeland and Taylor (2009) who model the evolution of property rights regimes at a country level. In their model, the government sets a harvest level that is tolerated, taking into account agents' incentive to cheat. Resource exploitation is thus dependent on what the government can enforce. Our paper shows that those findings may also translate to the case of community governance, where a community may agree on a second-best harvesting level to maintain cooperation.

Our model is presented in section 2. In section 3, we analyze endogenous capital in an open-access fisheries, which may present the case where cooperation has disappeared or has never evolved in the first place. Section 4 looks closer at the interaction of capital investments and social norms. Section 5 concludes, and briefly discusses our main findings.

\section{The model}

We assume that $N$ members of a closed community have access to a common pool resource. There are clear boundaries to the system, which means there is no migration of resource units or people in or out of the system. We assume that only villagers are tolerated on the resource grounds and no outside labor can be hired, which is often the case in common property regimes (Baland and Platteau, 1996; Ostrom, 1990). Consequently, the costs of fishing are not constant (as would be the case if there was a market wage), but marginally increasing, as each fisher has an increasing opportunity cost as fishing effort increases.

\footnotetext{
${ }^{1}$ Of course, there is a substantial literature on investment behavior and capacity adjustments in fisheries; see Nøstbakken et al. (2011) for an excellent review and Boyce (1995); McKelvey (1985); Clark et al. (1979) for key papers. However, no paper has explicitly considered that capital may evolve at a slower rate than variable inputs.
} 


\subsection{Resource dynamics and harvesting}

As a starting point, we take the canonical Gordon-Schaefer fisheries model (Clark, 1990). The change of resource abundance over time is dependent on the natural growth of the resource and the exploitation by fishers. The natural growth of the resource is described by the logistic growth function

$$
G(S)=r S(t)\left(1-\frac{S(t)}{S_{\max }}\right)
$$

125 where $S(t)$ is the resource abundance at time $t$. $S_{\text {max }}$ indicates the carrying capacity of the biological system and $r$ gives the intrinsic growth rate of the resource. We make the simplifying assumption that all short term variable inputs can be expressed in one variable, which we coin effort. The harvests of each agent $h_{i}(t)$ are linearly dependent on effort $\mathrm{e}_{i}(t)$, a technology variable $q_{i}(t)$ and the resource abundance and can be given as

$$
h_{i}(t)=\mathrm{e}_{i}(t) q_{i}(t) S(t) .
$$

The technology variable $q_{i}(t)$ is akin to the well-known catchability coefficient in the Gordon Schaefer model. The only difference is that the technology variable is varying over time and individuals. The harvest of all agents is summed to determine the total harvest $H=\sum_{i=1}^{N} h_{i}$. The change in resource abundance over time can then be determined by subtracting the aggregate harvest from the natural growth as given by

$$
\dot{S}=G(S)-H
$$

The net return on harvesting for each fisher is determined by his harvest and the cost of effort. Each harvested unit is sold for the constant price $P$. The costs of harvesting are convex, where the cost parameter for effort is given by $v$. This gives the net return on harvesting as

$$
y_{i}(t)=P \mathrm{e}_{i}(t) q_{i}(t) S(t)-v \mathrm{e}_{i}(t)^{2} .
$$

\subsection{Endogenous technology}

140 The technology variable $q_{i}(t)$ is dependent on the capital $k_{i}(t)$ that has been accumulated by agent $i$ and a capital to technology conversion rate $\gamma$. We assume that $q_{k}>0$ and $q_{k k}<$ 0 , which implies that there is a marginally decreasing return from capital on technological efficiency. Specifically, the relationship between capital and the technology variable is given by

$$
q_{i}(t)=\gamma k_{i}^{z}(t), \quad \text { where } \quad 0<z \leq 0.5 \text {. }
$$

The upper bound on $z$ assures that the relation between harvesting revenue and capital investments remains weakly concave, $\pi_{k k} \leq 0$. Inserting the technology variable into the harvest function would give the harvest function the form of a standard Cobb-Douglas production function, with inputs for labor (effort) and capital.

$$
h_{i}(t)=k_{i}^{z}(t) \gamma S(t) \mathrm{e}_{i}(t) .
$$


The investment to improve technological efficiency is costly. Due to insufficient capital markets, those investments have to be paid out of the stream of current incomes. Therefore, profit $\pi_{i}$ depends on revenues and costs of harvesting, as well as investment $I_{i}$ and is given as

$$
\pi_{i}(t)=k_{i}^{z} \gamma P S(t) \mathrm{e}_{i}(t)-v \mathrm{e}_{i}(t)^{2}-I_{i}(t) .
$$

The capital stock of each agent changes over time. Agents invest $I_{i}$ into their capital stock, while a fraction $\delta$ of their current capital stock depreciates. We assume that the capital is fully malleable, and the change of the capital stock $k_{i}$ can be given as

$$
\dot{k}_{i}=I_{i}-k_{i} \delta, \quad \text { with } \quad-k_{i} \leq I_{i} \leq \pi_{i} .
$$

Note that each agent possesses two control variables, effort $\mathrm{e}_{i}$ and investment $I_{i}$. We assume that the choice of effort is revised more frequently, and will be optimized based on the state of both the resource stock and the capital stock. Capital investments are a long-term decision, and we assume that agents make capital investments if they expect them to be profitable in the long run. Such choices may depend on social norms and are described in more detail in sections 3 and 4

\subsection{Evolution of social norms}

The socially optimal level of resource extraction is lower than the level which would maximize the income of an individual agent. If agents act selfishly this would lead to overexploitation and lower - if not zero - economic rents generated by the resource in equilibrium. $\quad 165$ Hence, we face a social dilemma.

To analyze the evolution of cooperative social norms, we rely on the evolutionary gametheoretic framework proposed by Sethi and Somanathan (1996). We assume that there are three groups of agents: (i) cooperators, (ii) defectors, and (iii) enforcers. The community comprises $N_{c}$ cooperators, $N_{d}$ defectors and $N_{p}$ enforcers, where $N=N_{c}+N_{d}+N_{p}$. ${ }_{170}$ Cooperators are willing to adhere to the social optimum, while defectors act selfishly and may overexploit the resource if this gives them higher utility. Enforcers adhere to the same harvest strategy as cooperators and punish defectors to enforce cooperation. Punishment is costly, both for the punisher, as well as for the receiver. An enforcer faces costs $\beta$ for each defector that is punished, while each defector is bearing costs $\alpha$ per punishment instance. Total utility is given as the sum of profits from harvesting $\pi$ and the costs of imposing or receiving sanctions. The utility for cooperators $\left(U_{c}\right)$, defectors $\left(U_{d}\right)$ and enforcers $\left(U_{p}\right)$ is determined by the following set of functions:

$$
\begin{gathered}
U_{c}(t)=\pi_{c}(t) \\
U_{d}(t)=\pi_{d}(t)-\alpha N_{p}(t) \quad \text { with } \quad \alpha>0 \\
U_{p}(t)=\pi_{c}(t)-\beta N_{d}(t) \quad \text { with } \quad \beta>0 .
\end{gathered}
$$

The utility of cooperators is only determined by profits, since they neither punish, nor are punished. For defectors, the utility loss is particularly high if $N_{p}$ is high, i.e. if there are many enforcers in the community. For enforcers, it is particularly costly if many defectors $\left(N_{d}\right)$ are in the community. Note that the monetary profits of enforcers and cooperators are identical. Enforcers, however, face the costs of punishing peers. The evolutionary 
process is based on the replicator equation (Taylor and Jonker, 1978) that determines the change of strategies. This process is based on imitation dynamics, where agents will revise their strategy if a better one is available. If a strategy gives higher than average utility, the fraction of agents using it increases. Formally, the number of players following strategy $x$, where $x=c, d, p$ is given by $N_{x}$. So the fraction of each strategy changing over time is given by the set of differential equations

$$
\frac{\dot{N}_{x}}{N}=\frac{N_{x}}{N}\left(U_{x}-\bar{U}\right), \quad \text { where } \bar{U}=\sum_{x=1}^{3} \frac{N_{x}}{N} U_{x}
$$

From equation 12 it follows that an equilibrium requires utility of all chosen strategies in the equilibrium to be the same. The system as proposed by Sethi and Somanathan (1996) has two stable equilibria: either full cooperation or full defection. A stable state with all three strategies present is not possible. If defectors are present, enforcers would perform strictly worse than cooperators, due to the strictly positive cost of punishing. A stable state consisting of cooperators and defectors is not possible, under the condition that $\pi_{d}>\pi_{c}$, as the the defector strategy strictly dominates the cooperator strategy in the absence of enforcers ${ }^{2}$ Lastly, a community comprising both enforcers and defectors cannot be a stable equilibrium, because a mixed community will always be attracted towards full cooperation or full defection. The intuition is that if the fraction of enforcers increases, relative utility of defectors decreases (as they are punished by more agents), leading to a further erosion of defection. For similar reasons, an increasing fraction of defectors will imply higher costs for enforcers and lead to an erosion of enforcers. Hence the system has two stable states: full defection or full cooperation. Fig. 1 illustrates the change in composition of strategies in a stable bioeconomic system and the attraction towards either full cooperation or full defection. The nature of both stable states will be described in more detail in section 4 .

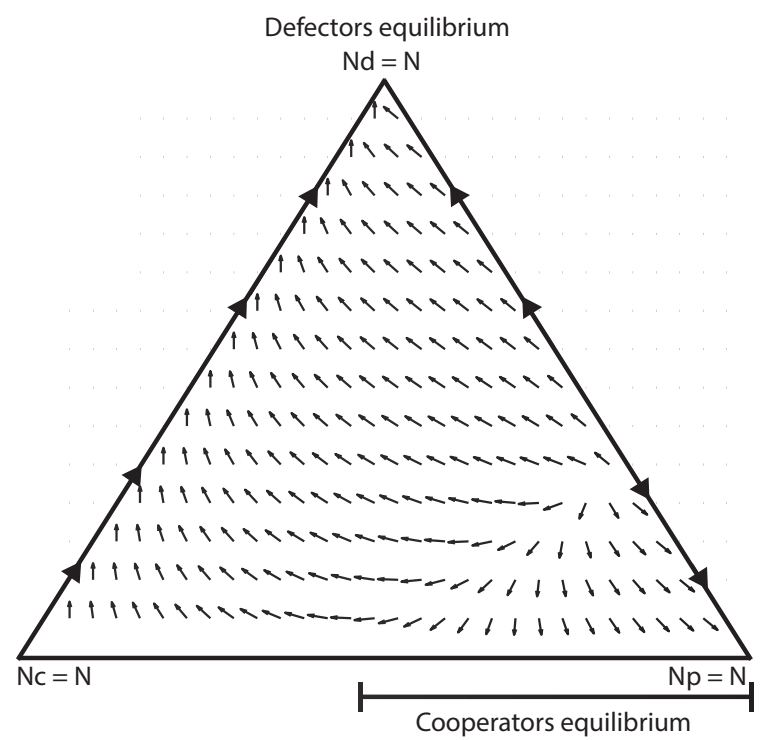

Figure 1: The figure illustrates how the composition of strategies changes, based on the current population. The corners of the triangle represent a population consisting of only one strategy. The lines between the corners represent some combination of two strategies, and in the interior all three strategies are present. The simulation shows the case where $\pi_{d}-\pi_{c}=40, N=100, \alpha=1, \beta=$ 0.8 .

\footnotetext{
${ }^{2}$ Note that cooperators and defectors can co-exist if profits are zero, which is ruled out in Sethi and Somanathan (1996). We explore this situation in section 4.4 .
} 
Table 1: List of assumptions used in the model and related literature

\begin{tabular}{|c|c|c|}
\hline Section & Model assumptions & Literature \\
\hline 2.1 & Gordon-Schaefer model for open-access fisheries & (Gordon, 1954, Clark, 1990) \\
\hline 2.2 & Harvesting efficiency dependence on capital & (Eigaard et al., 2014) \\
\hline \multirow[t]{2}{*}{2.2} & Malleability of capital, reversibility of investments & (Rust et al. 2016 ; Clark et al., 1979) \\
\hline & & (Clark, 1990 P.110), (Allison and Ellis, 2001) \\
\hline 3.13 .2 & Dynamic between effort and capital & $($ Nøstbakken et al. 2011 Clark 1990$)$ \\
\hline 2.2 & Myopic agents & (Yletyinen et al. 2018) \\
\hline 2.3 & Evolutionary game-theoretic framework & (Sethi and Somanathan, 1996) \\
\hline 2.3 & Replicator dynamic for social norms & ('Taylor and Jonker, 1978) \\
\hline 3.5 & Maximum economic yield as a benchmark & (Clark 1990 P.42-43) \\
\hline
\end{tabular}

\section{The open access equilibrium and social optimum}

In this section the open-access equilibrium is determined, followed by the socially optimal resource and capital stock. The social optimum is the stable state which maximizes the collective benefits and is only stable if all agents are cooperators or enforcers. The openaccess equilibrium is the stable state associated with the "defector equilibrium" of the social norms model of Sethi and Somanathan (1996), which implies that all cooperators have disappeared and everyone is defecting. Of course, the open access equilibrium also resembles a situation where social norms have never evolved in the first place and everyone has been pursuing his own interest from the start. In such a situation agents try to claim any resource rents available, which may happen by either investing effort or capital.

To determine the open-access equilibrium, we assume that all agents behave selfishly and try to maximize their immediate gains, consistent with an open access fishery. In doing so, they will change effort or the size of their capital stock if this will increase their income. A steady state implies that neither the resource stock, the capital stock, nor effort changes over time. In the paper we only present the case of $z=0.5$, as this yields easily interpretable closed form solutions ${ }^{3}$ We summarize all other key model assumptions and the literature related to each assumption in table 1 .

\subsection{Choice of effort - short run dynamics}

Each fisher decides how much effort to spend on harvesting the resource. This decision obviously depends on the resource stock, but also on the equipment he possesses. The optimal amount of effort can be found by deriving the profit function with respect to effort and setting it to zero, as given by $\frac{\partial \pi_{i}}{\partial \mathrm{e}_{i}}=\sqrt{k_{i}} \gamma S P-2 v \mathrm{e}_{i}=0$. Then, the optimal amount of effort 4 is given by

$$
\mathrm{e}_{i}=\frac{\sqrt{k_{i}} \gamma S P}{2 v} .
$$

\footnotetext{
${ }^{3}$ If effort is chosen optimally, the partial output elasticity of capital is equal to one in such case. This implies that a one unit increase in capital leads to a one unit increase in harvests, which is akin to the properties in the standard Gordon-Schaefer model. For values of $z<0.5$, we have a concave harvest function with respect to capital, so a one unit increase in capital leads to a less than one unit increase in harvests. It seems quite plausible to see those diminishing returns in real-world fisheries, though see Gordon (1954) for a discussion on why diminishing returns may not unfold in the fishing industry. For values of $z>0.5$, we have a convex harvest function with respect to capital, which means a one unit increase in capital leads to a larger than one unit increase in harvests. Those increasing returns to capital do not seem very realistic and at odds with economic principles, though see Mirza et al. (2019) for a model that features locally increasing returns to scale.

${ }^{4}$ As the second derivative is negative $\left(\frac{\partial^{2} \pi_{i}}{\partial \mathrm{e}_{i}^{2}}=-2 v\right)$, we can conclude that this is a maximum.
} 
We see that the agent uses more effort if (i) he possesses more capital $(k)$, (ii) the resource abundance $(S)$ is high, and (iii) sales price $(P)$ is high. Higher harvesting costs $(v)$ decrease the amount of effort. This condition for the allocation of effort 13 can be substituted into the harvest function (2), which gives

$$
h_{i}=\frac{k_{i} \gamma^{2} S^{2} P}{2 v} .
$$

This condition for the allocation of effort $(13)$ can be substituted into the profit function (7). This substitution simplifies further analysis as now profit is only dependent on investments and capital, but no longer on effort. Therefore,

$$
\pi_{i}=\frac{k_{i} \gamma^{2} S^{2} P^{2}}{4 v}-I_{i}
$$

\subsection{Choice of capital stock - long run dynamics}

The only variable which appears in the derivative is the state of the resource stock. We can solve for $S$ to obtain a threshold value of resource abundance $\hat{S}=\frac{2 \sqrt{\delta} \sqrt{v}}{P \gamma}$, which determines whether an investment will be profitable. The marginal profit from capital increases monotonically with resource abundance. Therefore, if the resource stock is above the threshold value $\hat{S}$ the agent can increase his income by increasing his capital stock, whilst at resource abundance levels below $\hat{\mathrm{S}}$ the agent will make a net loss on each unit of

\footnotetext{
${ }^{5}$ Obviously, this is a simplification, though in line with observations from the field, as descriped in Allison and Ellis (2001) p.383: "However, for most artisanal fisheries, and especially those in low-income countries, the assets tied up in fishing are not that great and mobility is relatively high." An alternative approach would have been to use non-malleable capital, i.e. non-reversible investments (cf. Rust et al. (2016); McKelvey (1985)), which is more realistic, but challenging, if not impossible to combine with a model of social norms. After all, there is strategic interaction, so that agents would have to from beliefs about investment of peers (potentially guided by norms) and the development of the stock.
} 
capital. This creates a bang bang solution with three types of solutions. If the resource stock is below the minimum threshold for investment, the agent stops his investments altogether and will disinvest if possible. When the stock is above the threshold, the agent will want to increase his capital stock, and at $\hat{\mathrm{S}}$ the agent will maintain his capital stock by replacing any depreciated capital. Therefore, investment can be given as

$$
I_{i}=\left\{\begin{array}{lll}
\pi_{i} & \text { if } & S(t)>\hat{S} \\
k_{i} \delta & \text { if } & S(t)=\hat{S} \\
-k_{i} & \text { if } & S(t)<\hat{S} .
\end{array}\right.
$$

To determine the nullcline for the capital stock, the results from equation 17 are inserted into the differential equation for capital, equation 8 . The nullcline for the capital stock is plotted in Fig. 2:

$$
\dot{K}=0 \quad \text { if } \quad \hat{S}=\frac{2 \sqrt{\delta} \sqrt{v}}{P \gamma}
$$

\subsection{Resource stock}

To determine how resource abundance is affected by harvesting, we insert the size of the aggregate capital stock $K=\sum_{i=1}^{N} k_{i}$ into the harvest function 14 , which gives aggregate harvests

$$
H(t)=\frac{K \gamma^{2} S^{2} P}{2 v}
$$

Total harvests increase linearly with the aggregate capital stock and quadratically with 275 the size of the resource stock ${ }^{6}$ The resource stock will be in equilibrium if harvests equal the natural growth, i.e. $r S\left(1-\frac{S}{S_{\max }}\right)=\frac{K \gamma^{2} S^{2} P}{2 v}$. This equation can be solved with respect to the size of the capital stock, giving the critical capital stock $\hat{K}$ needed to harvest the resource in equilibrium

$$
\dot{S}=0 \quad \text { if } \quad \hat{K}=\frac{2 r v\left(1-\frac{S}{S_{\max }}\right)}{P S \gamma^{2}}
$$

This critical capital stock $\hat{K}$ decreases as resource abundance increases, meaning that less 280 (more) capital is needed to have a high (low) resource level in equilibrium. Equation (20) gives the nullcline of the resource, which is shown graphically in Fig. 2.

\subsection{The open-access equilibrium}

For the complete bioeconomic system to be in a steady state both resource abundance and capital have to remain constant at the same time. We can find the equilibrium by substituting the investment threshold $(18)$ into the nullcline for resource abundance $(20)$. This yields the steady state values, corresponding to the intersection of two nullclines in Fig. 2.

\footnotetext{
${ }^{6}$ Considering that agents can have differing technology coefficients and effort levels, it may seem surprising that aggregate harvests rise linearly with aggregate capital stock. However, the linear relationship between individual capital and harvest makes it possible to determine the aggregate harvest directly from the aggregate capital stock.
} 


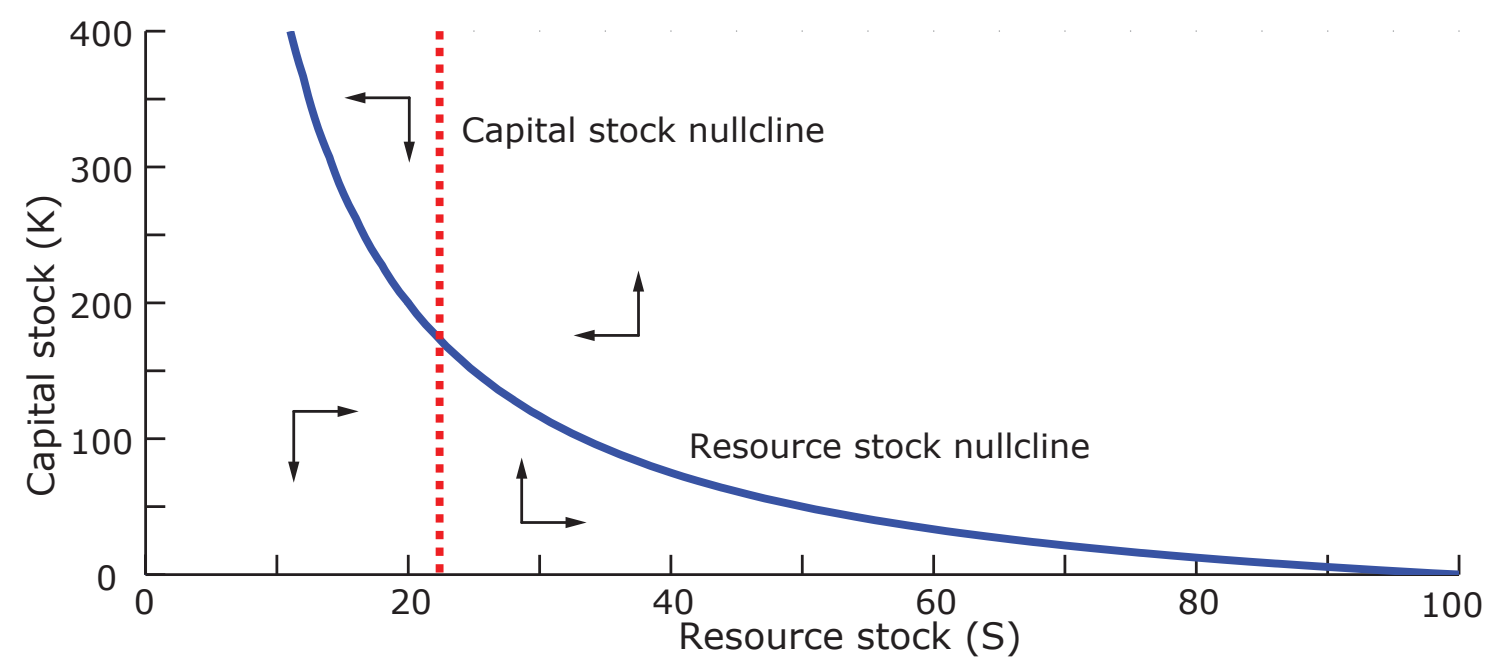

Figure 2: The capital and resource stock nullclines describe the dynamics of the system. The open-access equilibrium is located at the intersection of both nullclines. The arrows indicate the direction in which the variables would change over time.

$$
\hat{K}=\frac{r \sqrt{v}\left(1-\frac{2 \sqrt{\delta} \sqrt{v}}{P \gamma S_{\max }}\right)}{\gamma \sqrt{\delta}} \quad \text { and } \quad \hat{S}=\frac{2 \sqrt{\delta} \sqrt{v}}{P \gamma}
$$

At the investment threshold $\hat{S}$, no agent is able to raise his profit by either increasing harvesting effort or by investing in technological efficiency. At the open-access equilibrium in the Gordon-Schaefer model no economic rents remain (Seijo et al., 1998). Hence, our open access equilibrium is consistent with the Gordon-Schaefer model in that regard.

\subsection{Optimal management}

In this section, we are going to determine how the community can achieve the largest collective sustainable profit - the maximum economic yield. Maximum economic yield is a standard management objective, essentially maximizing the net present value using a zero percent discount rate. The main purpose of this analysis is to establish a benchmark for cooperation, which is why we refrain from using a positive discount rate - the insights would be similar, but the analysis would be unnecessarily complicated.

300 The cooperators agree on a socially optimal capital stock $K^{*}$, whilst allocation of effort remains dependent on the resource stock and the agent's capital stock; see equation (13). Each cooperator invests the fair share of capital, i.e. $k_{c}=K^{*} / n$. In equilibrium, the resource stock cannot change over time, meaning the harvest has to equal the natural growth of the resource. Maximum economic yield is found by solving the following problem

$$
\max \quad \pi=\frac{K \gamma^{2} S^{2} P^{2}}{4 v}-K \delta \quad \text { subject to } \quad G(S)=H(K, S) .
$$

305 The capital stock $\hat{K}$ that supports a sustainable resource stock, i.e. $\dot{S}(t)=0$, is given in equation 20 and substituted in the objective function 22 to obtain

$$
\pi^{*}=-\frac{r\left(S-S_{\max }\right)\left(\gamma^{2} S^{2} P^{2}-4 \delta v\right)}{2 \gamma^{2} S P S_{\max }},
$$


where $\pi^{*}$ indicates the profits that can be generated by sustainably harvesting the resource. Note that sustainable profits depend on only one variable: resource abundance. To maximize function (23) we derive it with respect to the size of the resource stock to yield

$$
\frac{\partial \pi^{*}}{\partial S}=-\frac{r\left(2 \gamma^{2} S^{3} P^{2}-\gamma^{2} S^{2} P^{2} S_{\max }-4 \delta v S_{\max }\right)}{2 \gamma^{2} S^{2} P S_{\max }} .
$$

Setting the derivative to zero gives an optimal level of resource abundance $S^{*}$ at which sustainable exploitation grants the highest aggregate profit 7 , which can be expressed as

$$
\begin{gathered}
S^{*}=\frac{S_{\max }^{2}}{36 A}+\frac{S_{\max }}{6}+A, \\
\text { where } A=\sqrt[3]{\sqrt{(B+C)^{2}-B^{2}}+B+C}, \\
\text { where } B=\frac{S_{\max }^{3}}{216}, \quad C=\frac{v \delta S_{\max }}{P^{2} \gamma^{2}} .
\end{gathered}
$$

\section{Community governance}

In our model, cooperators agree on a socially optimal capital and effort level that ensures a stable level of resource abundance at which economic rents are produced. The replicator dynamics (12) show that agents will be attracted towards the most successful strategy. To maintain a state in which the cooperative strategy remains dominant, it has to be the one offering the highest utility. Thus, for a cooperative stable state to be stable, the cost of being punished has to be higher than the additional revenue that could be attained from defecting. In the next section we analyze under which conditions a cooperative state is 320 stable.

\subsection{Cooperative stable state}

Within the framework of Sethi and Somanathan (1996) it is impossible for cooperators and defectors to co-exist in a stable state. Hence, the cooperative stable state implies that all agents are cooperating and no one is defecting. To ensure that a cooperative state is stable, the change in both resource and capital stock over time has to remain zero. Furthermore, no agent should be tempted to defect and utility of cooperating should be strictly higher than utility of defecting. Note that the utility of cooperators is equal to enforcers if defectors are absent and given by

$$
U_{c}=\frac{k_{c} \gamma^{2} S^{2} P^{2}}{4 v}-k_{c} \delta
$$

As all agents are cooperating, their capital is optimized to sustainably harvest the resource stock, and effort is chosen optimally, as given by equation (13). While there is no possibility to increase profits by increasing effort, agents could be tempted to defect by making investments $I_{d}$ into the capital stock that go beyond the cooperative level. These

\footnotetext{
${ }^{7}$ The second derivative is given by, $\frac{\partial^{2} \pi^{*}}{\partial S^{2}}=-\frac{r\left(\gamma^{2} S^{2} P^{2}+4 \delta v S_{\max }\right)}{\gamma^{2} S^{3} P S_{\max }}$, where all parameters are non-negative. As the second derivative is strictly negative we can conclude that the reported solution is a maximum.
} 
investments could increase the agent's individual profits, but would trigger punishments

$$
U_{d}=\frac{\left(k_{c}+I_{d}\right) \gamma^{2} S^{2} P^{2}}{4 v}-\left(k_{c}+I_{d}\right) \delta-\alpha N_{p}
$$

A cooperator will only be tempted to defect and overinvest, if it increases his utility. Hence, we need to compare the utility functions of cooperators (26) and defectors (27). In equation (28), we see that the difference in utility between cooperators and defectors is composed of the return on the investment and the punishment by enforcers. Defection occurs if the revenue gained from the overinvestment is greater than the costs of the overinvestment and the cost of being punished, as given by

$$
U_{d}-U_{c}=\frac{I_{d} \gamma^{2} S^{2} P^{2}}{4 v}-I_{d} \delta-\alpha N_{p}
$$

In the cooperative stable state each unit of capital invested has a positive net return, while punishment is constant and independent on the size of the investment. In the following two sections we will analyze how investments affect cooperation when the limit to investments is either set exogenously or is determined endogenously by the agents' total profit in the previous period.

\subsection{Exogenous investments}

In this section we describe how cooperation is affected by investments when the limit to investment is set exogenously. A cooperative state can be invaded if defecting yields a higher utility than cooperating. The investment capability of a potential defector $I_{d}$ is salient, because the investment needs to be large enough to negate the received punishment. This means that as the punishment capacity of the community rises, larger investments are necessary to pass the investment threshold $\hat{I}_{d}$, beyond which larger investments make defection profitable; see Fig. 3.

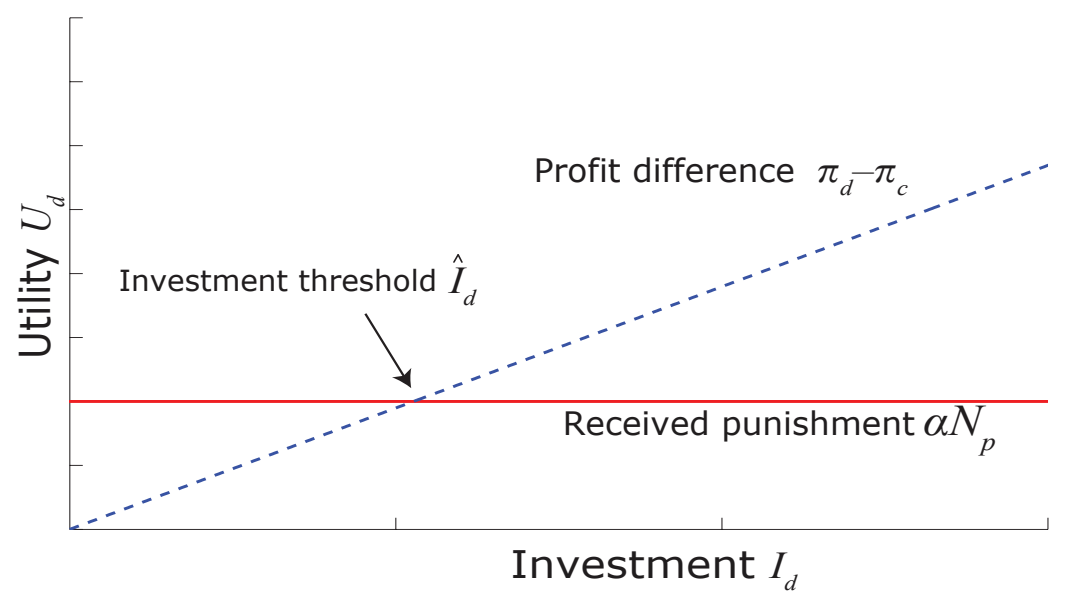

Figure 3: There is an investment threshold $\hat{I}_{d}$ at which utility from cooperation and defection are the same. Any higher investment level will favor defection, while any lower investment level favors cooperation. The intuition behind it is that the income of the agent rises linearly with investment, while the punishment received for this 'illegal' investment is constant. 
Essentially, whether cooperation can be enforced is determined by the ability to invest $I_{d} \quad 355$ and the received punishment $\alpha N_{p}$. Obviously, the ability to administer severe punishments helps in maintaining a cooperative stable state. The critical level of enforcement needed to maintain a cooperative stable state is given by

$$
\alpha N_{p}=\frac{I_{d} \gamma^{2} S^{2} P^{2}-4 I_{d} v \delta}{4 v} .
$$

We find that higher enforcement is needed if the resource stock is high, the sales price is high, and the costs of effort are low. Indeed, these are all factors that make harvesting more profitable, increasing the temptation to defect. The minimum investment needed to compensate for the received punishment can be determined by

$$
\hat{I}_{d}=\frac{4 v N_{p} \alpha}{\gamma^{2} S^{2} P^{2}-4 v \delta} .
$$

We find that larger investments are needed to break even $\left(I_{d}\right.$ is larger) if there are more enforcers in the community, and punishment is more effective. The investment threshold is smaller when the resource stock is large, the sales price is high and the technology $\gamma$ is 365 more efficient.

The interaction between investment and punishment is influenced by a third variable, the level of resource abundance at the cooperative steady state. The increase in revenue by each invested unit of capital is positively dependent on the level of resource abundance. Less punishment capacity would be needed to enforce a cooperative stable state at lower levels of resource abundance. The highest possible resource stock at which a cooperative stable state can be enforced, can be determined by

$$
\bar{S}=\sqrt{\frac{4 v N_{p} \alpha+4 I_{d} v \delta}{I_{d} \gamma^{2} P^{2}}} .
$$

This shows that aside from stronger enforcement there is a second device which can control whether the system can be invaded by defectors, and that is the agreed upon size of the resource stock. When enforcement power is insufficient to enforce the first best, cooperative agents can agree to harvest the resource at a lower level of resource abundance. To sum up, when investment capacity is determined exogenously there are three different types of stable state possible.

$$
\bar{S}=\left\{\begin{array}{lll}
S^{*} & \text { if } & \bar{S} \geq S^{*} \\
\bar{S} & \text { if } & \hat{S}<\bar{S}<S^{*} \\
\hat{S} & \text { if } & \bar{S} \leq \hat{S}
\end{array}\right.
$$

1. There is enough enforcement power to achieve the socially optimal state, as no one is able or willing to make an investment large enough to destabilize it. The resource will be harvested sustainably at the optimal level of abundance $S^{*}$.

2. The enforcement power is not strong enough to achieve the socially optimal state, but a resource stock higher than the open-access equilibrium can be enforced, creating a suboptimal cooperative stable state at the resource level $\bar{S}$.

3. There is no enforcement power in the community, as all agents have defected. The 385 only stable state is the open-access equilibrium. The resource is harvested at the abundance level $\hat{S}$. 
Table 2: Model parameters

\begin{tabular}{|l|c|r|}
\hline Model parameters & Description & Value \\
\hline$N$ & Number of agents & 100 \\
$r$ & Intrinsic resource growth rate & 1 \\
$S_{\max }$ & Carrying capacity & 100 \\
$P$ & Resources sales price & 200 \\
$v$ & Cost of effort & 100 \\
$\gamma$ & Capital to efficiency conversion rate & 0.002 \\
$\delta$ & Capital depreciation rate & 0.05 \\
$\alpha$ & Cost of being punished & 10 \\
$\beta$ & Cost of punishing & 0.5 \\
$I_{d}$ & Investment capacity & 400 \\
\hline
\end{tabular}

By changing various key parameter we analyze how they affect the equilibrium resource stock of the open-access fisheries $\hat{S}$, optimal management $S^{*}$ and the highest enforceable cooperative stable state $\bar{S}$. We assess the effect of changing the resource price $P$, the costs of effort $v$ and the capital-technology conversion rate $\gamma$, by plotting the equilibrium resource stock as a function of these parameters; see Fig. 4 and Table 2 for parameter values. When the price of the resource rises and the costs of harvesting decrease, the resource abundance at which the maximum economic yield is attained $S^{*}$ decreases and approaches the maximum sustainable yield $\left.\right|^{8}$ When price $(P)$ rises or when the cost of harvesting $(v)$ or efficiency $(\gamma)$ drops, the increase in revenue per unit of (over-)invested capital increases, decreasing the highest enforceable cooperative stable state $\bar{S}$. The openaccess equilibrium stock $\hat{S}$ gradually increases when the cost of effort increases. However when resource prices or the capital-technology conversion rate increase it rapidly declines.

400 Note that if the highest enforceable resource stock $\bar{S}$ is higher than the optimal resource stock $S^{*}$, it means that the optimal policy can be enforced. Similarly, no management is needed if the optimal resource abundance and open-access equilibrium $\hat{S}$ coincide.

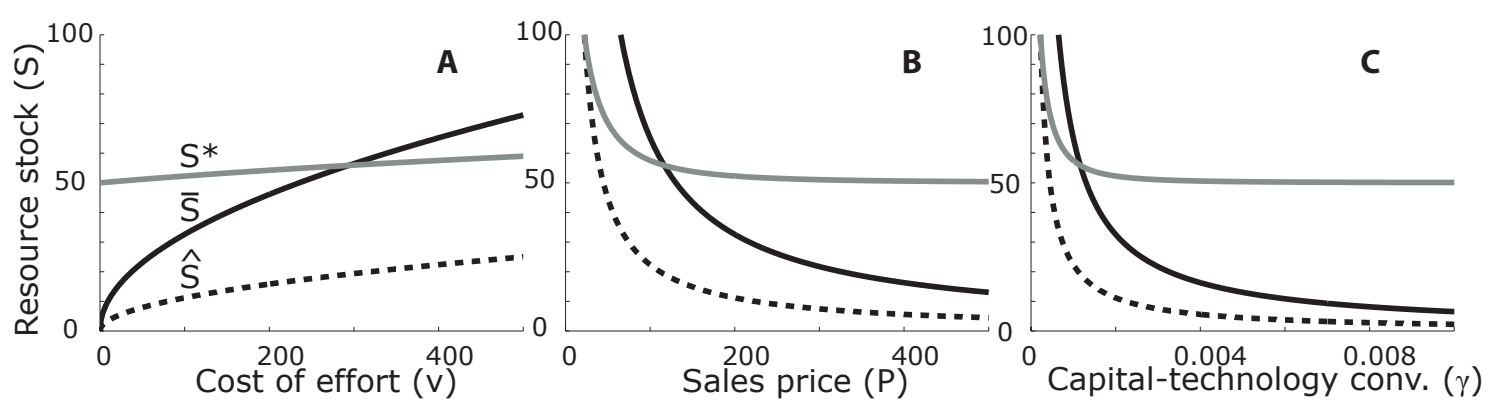

Figure 4: Each of the three panels shows the equilibrium resource abundance of the possible stables states as the function of one variable; A) Cost of effort $v$. B) Price of the resource $P$. C) Conversion rate from capital to technological efficiency $\gamma . P$ and $v$ are varied between 0 and 500 and $\gamma$ between 0 and 0.01, whilst all other variables are kept constant at the values in table 2. The solid grey line indicates MEY $S^{*}$, the dashed line the open-access resource stock $\hat{S}$ and the black solid line shows the maximum resource abundance that can be enforced $\bar{S}$.

\subsection{Endogenous investments}

In this section investment capacity is endogenously determined. The agents have no access to capital markets, so investments have to be paid out of the stream of current incomes.

\footnotetext{
${ }^{8}$ Maximum sustainable yield is a policy objective with the aim to maximize the equilibrium harvests. For the standard logistic growth function this is achieved at resource levels of half the carrying capacity, which in this case is 50 .
} 
Considering that each unit of capital has a positive net return when the resource stock is at a higher level than the open-access equilibrium, a defector would always want to maximize his investment. The maximum investment an agent is able to make, is equal to his profit from the previous period. We analyze whether a cooperative state can be invaded, so the maximum investment made by a potential defector is equal to the profit of a cooperator in the stable state as determined in equation $(23)$, thus $I_{d}=\pi_{i, t-1}=\pi_{c}^{*}(S) .9$

The agreed upon resource stock at the cooperative equilibrium now determines the temptation to defect in two ways. The first being the revenue earned per invested unit of capital and the second being the investment capacity of potential defectors. An increase in the cooperators profits would thus have the adverse effect of increasing the investment capacity of potential defectors.

As seen in Fig. 5, the investment capacity rises until the resource stock reaches the first best solution (maximum economic yield). At resource stock levels higher than the first best, the size of the defectors investment capacity declines, but the profit gained from defecting continues to increase due to the higher return on each invested unit of capital. As the stock approaches the carrying capacity the declining investment capacity becomes limiting for the defector's profits.

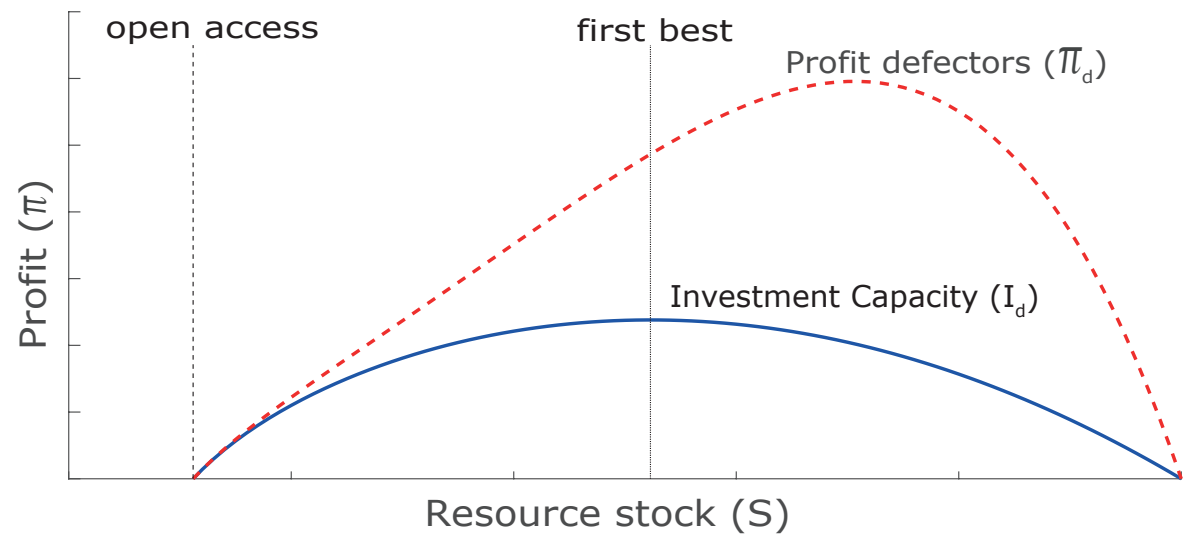

Figure 5: The graph shows the profit for defectors and their investment capacity as a function of the resource stock. The investment capacity is equal to the profit of cooperators. The two vertical lines indicate the open-access resource stock and the first best for cooperators.

Fig. 6 shows how the temptation to defect, given by the difference in profits between defectors and cooperators $\left(\pi_{d}-\pi_{c}\right)$ varies with the size of the resource stock. As before, the punishment defectors receive for overinvesting $\left(\alpha N_{p}\right)$ is independent of the resource stock and a cooperative stable state can be maintained if the punishment is larger than the profit difference.

When investment capacity is determined endogenously, there are two resource stock levels ' $S_{A}$ ' and ' $S_{B}$ ' at which the additional profits from harvesting gained by defecting are equal to the received punishment. These resource stock levels can be interpreted as threshold values, as cooperators could agree to either harvest the resource at levels lower than ' $S_{A}$ ' or higher than ' $S_{B}$ ' and cooperation would be stable. However, a cooperative state would not be stable in-between those values.

The difference in profits between cooperators and defectors is the same at both threshold values. However, the first threshold value $S_{A}$ is characterized by a relatively low resource stock, while $S_{B}$, is characterized by a high resource stock level. As the investment has

\footnotetext{
${ }^{9}$ If punishments are monetary, the investment potential of a defector is reduced by any punishments received. We explore this assumption in section 4.4 .
} 


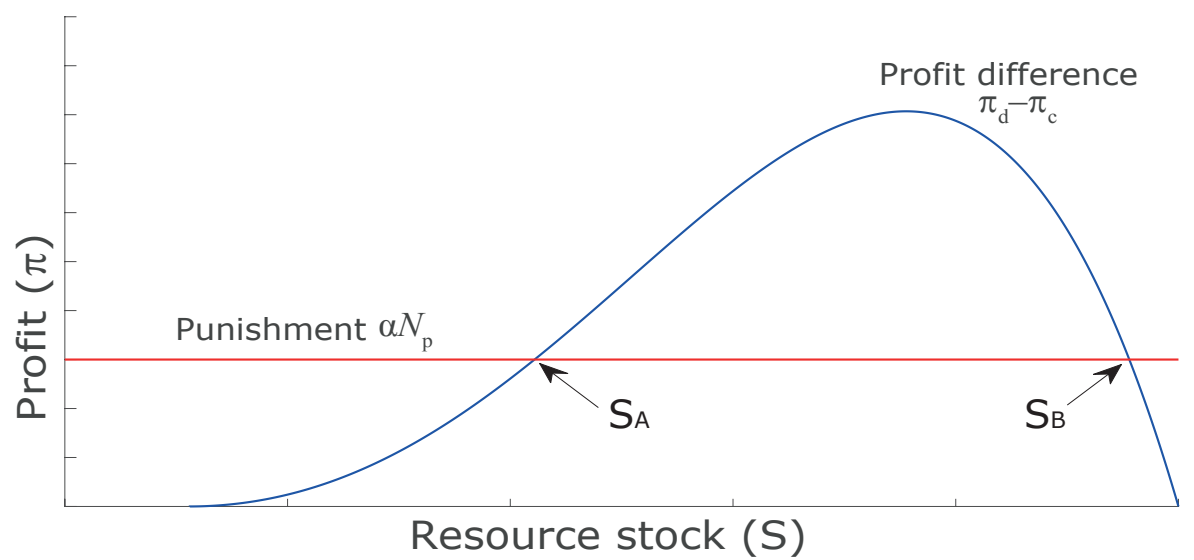

Figure 6: The graph shows the difference in profit between defectors and cooperators and the punishment defectors would receive. At two points the lines intersect, these are threshold points $S_{a}$ and $S_{b}$. The difference in profits is only plotted if agents make positive profits by following their chosen strategy.

to be paid out of the agents' stream of incomes, the investment capacity reduces as the profits diminish. If the resource is harvested sustainably at very high levels of abundance, profits are relatively low. Even though the return on each invested unit of capital is very 440 high at $S_{B}$, agents are not able to make an investment large enough to destabilize the cooperative state. Which allows for cooperation to be stable at high levels of resource abundance.

We can numerically determine $S_{A}$ and $S_{B}$ by solving equation (28) with $I_{d}=\pi_{10}^{10}$, which after substitution can be written as

$$
U_{d}=U_{c} \quad \text { if } \quad \frac{r\left(S_{\max }-S\right)\left(\gamma^{2} S^{2} P^{2}-4 \delta v\right)^{2}}{8 \gamma^{2} S P v S_{\max }}-\alpha N_{p}=0
$$

At both threshold values a small increase in the gain from defecting could induce agents to adopt the defector strategy and destabilize the cooperative state. This may be triggered by an exogenous shock, such as an increase in resource price, technological efficiency or a decrease in opportunity cost or depreciation of capital. In Fig. 7 we plot the threshold values $S_{A}$ and $S_{B}$, indicating the range in which cooperation is stable.

450 Fig. 7 illustrates how the threshold values vary dependent on the following parameters: price $(P)$, cost of effort $(v)$, the capital to technology conversion rate $(\gamma)$ and the degree of capital decay $(\delta)$. The upper threshold value $S_{B}$ is generally close to carrying capacity, whilst the lower threshold value is similar to those plotted in Fig. $4{ }^{11}$ Enforcement becomes more difficult as either prices or the capital to harvesting efficiency conversion rate increases. An increase in the costs of effort or the rate of capital decay increases the range in which a cooperative stable state is possible.

To conclude, when investment capacity is limited by previously earned profits, cooperation is stable above and below separate threshold values of the resource stock. When the resource stock is sustainably exploited at levels below $S_{A}$ or above $S_{B}$, agents do not have enough income to make an investment large enough to offset the punishment they will

\footnotetext{
${ }^{10}$ No satisfactory analytical solution could be obtained and therefore we resort to a numerical analysis. Solving equation (33) for $\mathrm{S}$ yields 5 solutions, three of these are always outside of the used parameter space. Therefore these are omitted.

${ }^{11}$ All parameters are given in Table 2 except the resource sales price, which is $P=100$.
} 
receive for defecting. This is in contrast to when exogenous investments are available, as then a cooperative stable state at high levels of resource abundance would not be possible.
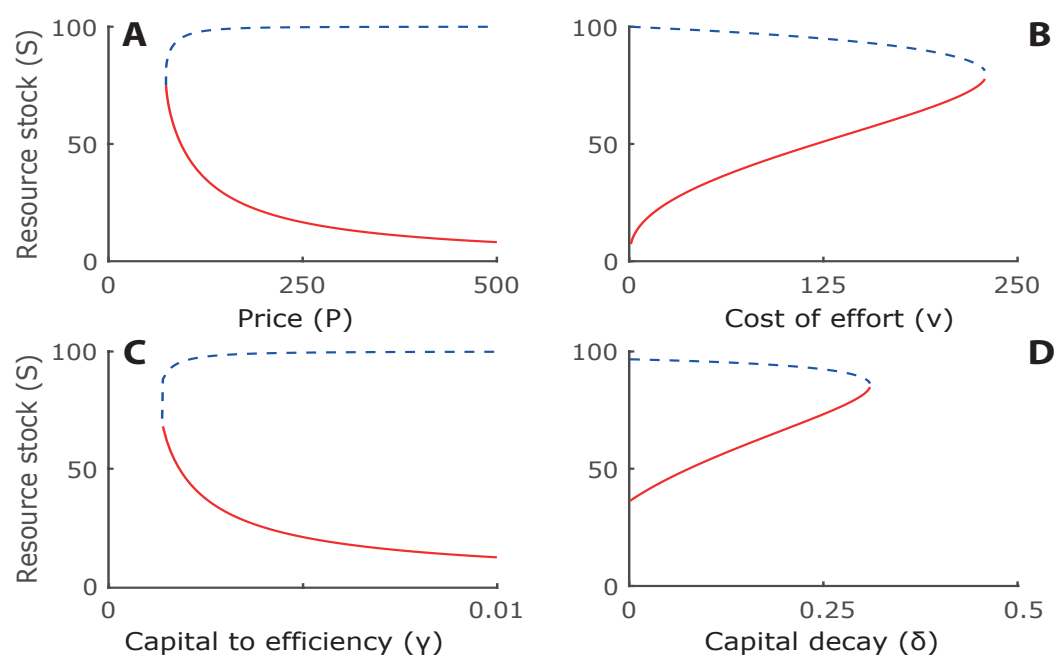

Figure 7: Each of the four graphs shows at which levels of the resource stock cooperation would be possible as a function of one parameter; A) Price of the resource $P$, B) Cost of effort $v$, C) Conversion rate capital to technological efficiency $\gamma$, D) Capital decay $\delta$. The dashed blue line shows the upper threshold value $S_{B}$ and the red solid the lower threshold value $S_{A}$. No cooperative equilibrium is possible in the area between the lines. When there are no lines for a given parameter value, this indicates that cooperation is possible at every level of the resource stock.

\subsection{Transition dynamics}

In this section we determine to which stable state the system converges when out of equilibrium. We run the model as a system of differential equations, where we vary the starting capital stock and the starting resource stock. The dynamics are explained using multiple time series which illustrate the different manners in which the system can develop.

We assume that cooperative agents behave in the following manner. In the initial period cooperators and enforcers set a target for the cooperative resource stock, $\bar{S}$. All agents receive an equal share of the capital stock necessary to harvest $\bar{S}$ sustainably as determined by equation $(20)$. We denote the aggregate starting capital stock as $K_{c}$, of which each agent receives $k_{c}=K_{c} / N$. At each positive starting level of the resource stock, the system will converge to $\bar{S}$ if harvested with the aggregate capital stock $K_{c}$.

Defectors start with the same capital stock as cooperators. However, they maximize their income by investing their profits according to equation (17). Their investment capacity is determined endogenously, as specified in section 4.3, with the added assumption that punishments are monetary and therefore reduce investment capacity, thus $I_{d, t}=\pi_{d, t-1}-$ $\alpha N_{p, t-1}$. As a consequence defectors are only able to make a positive investment if the gains from harvesting are higher than the received punishment. For simplicity we assume that all defectors hold the same representative capital stock. $\sqrt{12}$ The capital that defectors have in excess of $k_{c}$ is denoted as $k_{d, t}$. We simulate the model by running the differential equations for resource abundance (3), capital stock (8) and agent strategies (12) until an

\footnotetext{
${ }^{12}$ Defectors can increase their capital stock each period. An agent that has switched to the defector strategy in $t=1$ would have a different capital stock than an agent that has switched in $t=2$. Accounting for this heterogeneity would require an agent-based modelling approach.
} 
equilibrium is reached 13

The upper panel of Figure 8 shows to which equilibrium the system converges based on the starting resource stock $S_{0}$ and the cooperative capital stock $K_{c}$. The blue line indicates the resource abundance at the cooperative stable state, $\bar{S}$, as determined by the capital stock $K_{c}$. The system converges to the open-access equilibrium if the starting conditions are between the two solid black lines. Below the lower black line, and above the upper black line, the system converges to a cooperative stable state.

490 Within figure 8 there are four initial conditions marked with A,B,C and D. The correspondingly marked panels show how the system dynamics unfold at these points. Time series A illustrates how the system develops if the cooperative capital stock $K_{c}$ is high enough to deter defection. The number of defectors declines to zero and the resource
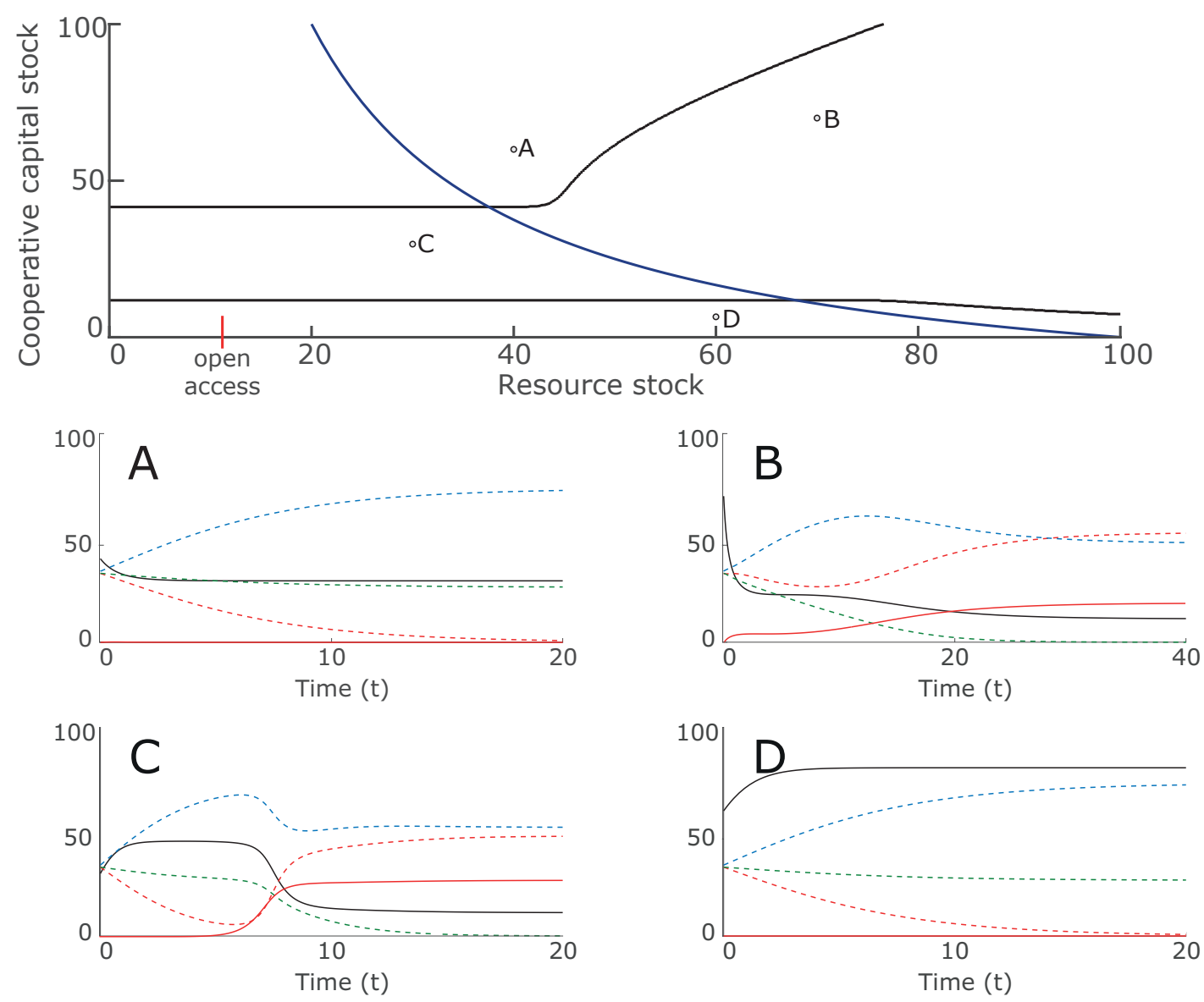

Figure 8: The upper panel illustrates the behavior of the system with different initial conditions A-D for initial resource stock and cooperative capital stock $k_{c}$. The blue line indicates the resource abundance at the cooperative stable state, as determined by the cooperative capital stock. If the starting conditions are between the two black lines, the system will converge to the open-access equilibrium. Below the lower black line, and above the upper black line, the system converges to a cooperative stable state. Panels A-D show the dynamics of the system at points A,B,C and D. The lines represent the following variables: black solid $(S)$, red solid $\left(10 k_{d}\right)$, red dashed $\left(N_{d}\right)$, green dashed $\left(N_{p}\right)$, blue dashed $\left(N_{c}\right)$. We assume that in the first time period the strategies are distributed evenly $\left(N_{p}=33, N_{d}=33, N_{c}=34\right)$ and set $\alpha=0.8$; all other parameters are set according to table 2. Panel specific parameters, A: $\left(\hat{k}=60, S_{0}=40\right), \mathrm{B}:\left(\hat{k}=70, S_{0}=70\right)$, $\mathrm{C}:\left(\hat{k}=30, S_{0}=30\right), \mathrm{D}:\left(\hat{k}=6, S_{0}=60\right)$.

\footnotetext{
${ }^{13}$ Simulations were run in the GRIND package for Matlab, http://www.sparcscenter.org/resources/dynamical-modelling-tools.html
} 
stock converges to the cooperative target stock. All defectors switch to the enforcer and cooperator strategy. We see that the share of enforcers drops slightly over time, as they switch to the cooperator strategy due to the cost of punishing defectors. At starting point $\mathrm{B}$, the initial resource abundance is substantially higher than the cooperative target stock, opening a window for defection to invade the cooperative equilibrium. Due to the higher stock, the profits of all agents are temporally higher, which increases the investments capacity of defectors and making defecting the most profitable strategy. Therefore, the share of enforcers drops rapidly, and the system converges to the open-access equilibrium.

The time plot at starting point $\mathrm{C}$ shows the case where the cooperative capital stock is too low to deter defection. Initially, defection is not profitable, but an erosion of enforcement is taking place as enforcers switch to a cooperative strategy. Approximately at $t=7$, the number of enforcers falls below the minimum needed to prevent defectors from accumulating capital, and consequently $k_{d}$ starts to increase. Due to the increase in capital, defecting becomes profitable and more agents switch to the defector strategy. Enforcement power continues to drop and the resource stock converges to the open-access equilibrium. The time series at starting point D illustrates the case for low levels of $k_{c}$. Due to the low starting capital of all agents, the profits from harvesting are limited. Hence, defectors are unable to increase their capital stock and the number of defectors decrease over time. The resource stock approaches the equilibrium stock $\bar{S}$.

From the time series we observe that preventing defectors from accumulating capital is pivotal in maintaining cooperation. Investments increase profits of defectors, which further increases investments and widens the gap in profits between cooperators and defectors. Therefore an important tipping point exists at the point where defectors profits exceed the received punishment, $\pi_{d, t-1}>\alpha N_{p}$.

We also observe that even if the initial conditions favor cooperation, defection can invade if the number of enforcers erodes over time. Under the condition that defectors are not able to make any investments, e.g. $k_{d}=0$, the profits from harvesting are identical for all strategies $\pi_{d}=\pi_{c}=\pi_{p}$. If this condition is met, the change of strategies over time is completely driven by the cost of punishing, and the cost of being punished. Hence, as long as defectors are present, enforcers will be tempted to become cooperators (and stop enforcing). The system will flip towards a defective stable state if the remaining number of enforcers becomes insufficient to prevent investments by defectors.

The two horizontal lines in figure 8 are located at the points where the remaining number of enforcers is sufficient to prevent investments, $\alpha N_{p}=\pi_{c}(\bar{S})$. The necessary enforcement power needed to maintain the cooperative equilibrium is a function of the cooperators profits, and thus $K_{c}$. The lines bend outward at higher levels of the starting resource stock, which implies higher initial profits, which allows defectors to make investments and invade the cooperative equilibrium.

In time series $\mathrm{B}$ and $\mathrm{C}$ we see that defectors and cooperators co-exist at the open-access equilibrium resource stock $(\hat{S})$. As mentioned in section 2.3 a cooperator-defector equilibrium is not possible if the profits from harvesting are positive. If punishment is absent $\pi_{d}>\pi_{c}$ implies $U_{d}>U_{c}$. However at $\hat{S}$ the average profit per unit of capital is zero, 535 and therefore the profit from harvesting for both strategies is zero. As the profits for both strategies are equal and there is no punishment a cooperator-defector equilibrium is possible at $\hat{S}$ provided that enforcers have disappeared. 


\section{Conclusion and Discussion}

540 It is a well established idea that community arrangements to harvest a resource sustainably can be undermined by continuous technological improvement in harvesting efficiency (Richter and Dakos, 2015; Taylor, 2011). In particular, investment in fishing capacity may lead to overcapacity that jeopardizes successful management of a fishery (Eigaard et al. 2014). We formalize these observations in a mathematical model to explore under which conditions social norms of cooperation erode, but may also adapt in light of the possibility to invest in fishing capital. Our paper points to an important tension in the field. If investments can be financed via exogenous capital markets, a large resource stock would trigger high investments, as profits can be made by exploiting the resource. If investments are endogenous and have to be financed through the current stream of incomes, low levels of capital would not generate the necessary income to support such large investments and stable cooperation may be observed at very high resource levels.

We added technological efficiency as an endogenously determined variable in the GordonSchaefer model, treating capital as a slowly changing variable and effort as a fast variable. Capital investments determine the harvesting efficiency of fishing vessels which

555 consequently influences allocation of harvesting effort. This has been integrated in the evolutionary game theoretic framework developed by Sethi and Somanathan (1996) in which social norms of cooperation regarding capital investments evolve over time ${ }^{14}$

Our model shows that in an open access regime, the cost and depreciation rate of capital investments are important in determining the resource abundance at the open-access equilibrium. Further, we find that cooperative resource exploitation can be destabilized by the potential to make large capital investments, and may be further challenged by high prices or low costs of effort. Finally, we find that communities have an interesting device at their disposal to discourage agents from defecting: the collectively agreed resource stock. When the regulatory power is insufficient to enforce optimal management, cooperative resource exploitation can be protected by lowering the level of abundance at which the resource is exploited.

To protect cooperative resource exploitation it is important to understand what incentives motivate fishers to refrain from selfish behavior such as illegal fishing or over-investing. Reducing incentives to cheat by lowering the resource stock is not socially optimal, but

570 could help prevent collapses to open-access in situations where enforcement capacity is limited. The results from our model support the idea established by Copeland and Taylor (2009), that when regulatory power is insufficient to dissuade agents from over-harvesting by punishment, it can be compensated for by reducing the incentives to cheat. Copeland and Taylor (2009) classified economies into three distinct groups. The first group consists of so called "Hardin economies", which lack the power to enforce any regulation. Resources in these economies will be depleted and harvested at the open-access equilibrium. The second group, "Ostrom economies" have the regulatory power to enforce suboptimal harvesting policy. However if they were to attempt to enforce the optimal harvesting policy, the incentive for agents to cheat would outweigh the expected punishment. The

580 last group, "Clark economies" have sufficient regulatory power to enforce the optimal harvesting policy (Copeland and Taylor, 2009). The three distinct economies devised by

\footnotetext{
${ }^{14}$ If capital and effort were revised simultaneously, the model would require a different setup. First, one would have to solve the use of inputs jointly, which is possible if one departs from the Gordon Schafer model. Using a model with decreasing returns to scale (e.g. Cobb Douglas technology), one would be able to find some kind of optimal mix of capital and effort; see for example Richter et al. (2018). Second, and more fundamentally, it is not so clear what cooperators would coordinate on (low effort, low capital or both). So it is not obvious how our findings translate to such setting.
} 
Copeland \& Taylor closely resemble the three types of stable states we presented in equation (32). Thus, we show that these results carry over to the case where not a regulator sets a harvesting policy, but it is in the hands of local communities guided by social norms. Our results could also be relevant in the debate concerning community governance structures. The assumption that people always try to maximize their own short term benefits has been challenged, and an increasing awareness has developed for other concepts such as trust, social norms and conditional cooperation (Janssen, 2015). Informal institutions that have developed over time, rely on the cooperation of exploiters and the willingness to impose sanction on free riders to succeed (Vollan and Ostrom, 2010). The imposed management can often be suboptimal with regard to bioeconomic theory, but allows for the resource to be harvested sustainably. Due to the theoretical nature of the work, we can obviously not conclude how relevant these mechanisms are in the field. However, the main implications of our work could be tested using case studies or economic experiments. In particular, it would be interesting to investigate how important technology is compared to other variables when considering sustainability in the commons (Ostrom, 2009).

A key feature of our model is that capital is the slow control variable, while effort is the fast one. The importance of fast-slow processes in social-ecological systems has been pointed out before (Crépin, 2007, Crépin et al., 2011; Walker et al., 2012). Those papers have considered fast-slow dynamics of state variables (e.g. corals and fish stock), while we consider time scales of control variables. Similar in this respect, Biggs et al. (2009) investigate how regime shifts can be avoided if they are triggered by either mechanisms which can be manipulated rapidly (fishing effort) or only gradually (coastal development). Indeed, the importance of time scales on sustainability and resilience of social-ecological systems has been increasingly recognized (Biggs et al., 2012). The challenges for modellers is to formalize and parameterize models incorporating different time scale, without drowning in complexity.

Any model, such as this one has limitations. First, while our model is deterministic, in reality the ecological or socioeconomic system may be exposed to natural variation. The transition dynamics in section 4.4 show that a higher resource stock, for example brought about by natural variation, increases profits and therefore allows defectors to invest more, potentially eroding cooperation. In such case, cooperation can be maintained if the system is sufficiently far from a threshold value and enough enforcement power is present to prevent investments from accumulating. However sufficiently large shocks in resource growth may trigger a shift from cooperation to defection.

Second, we follow Sethi and Somanathan (1996) in assuming that punishment is constant and independent of the severity of the infraction. It would be an interesting extension to consider punishment strength to be conditional on the magnitude of defection, i.e. the size of the investment. It is not obvious whether it would be better to be either strict or lenient on small violations, as strict punishments would discourage defection, but also pose higher costs on enforcers.

Third, we assume that capital is malleable, which is not implausible for a small scale fishery. However, assuming some kind of hysteresis and irreversibility in investments would certainly be more realistic (Huang and Smith, 2014, Dixit, 1992). Such an approach would require agents to form expectations about the future, and make optimal decisions in such context. In our model agents are myopic and do not form beliefs about social and resource dynamics, which is in line with how social norms are usually modelled in the literature. In reality, agents are probably not as rational as assumed in optimal investments models, nor as myopic as assumed in many evolution of cooperation models. Yet, a bridge between these two approaches is missing in the literature. This would certainly be an interesting 
avenue for further research and could also potentially reconcile the two polar assumptions in classical game theory (full rationality) and evolutionary game theory (myopia). One would expect that the degree to which fishers form beliefs and also adapt to the future depends on the underlying uncertainty and volatility of their environment, though the empirical evidence is sparse; but see Yletyinen et al. (2018).

Our results raise one important policy question, and that is how external authorities can prevent the erosion of cooperative harvesting norms. First, dependent on the source of the investments, the regulator could promote cooperation by implementing policies affecting key economic parameters, such as the cost of effort (see Fig. 4 for exogenous 640 investments and Fig. 7 for endogenous investments). Altering the price and cost structure is considered an important tool to discourage illegal and unregulated harvesting (Gallic and Cox, 2006). Second, there is also the question at what point an external regulator should step in, for example by introducing external fines and monitoring. It has been observed that rules established by external authorities, such as governments, aimed at increasing the productivity of such resources can have negative consequences. The success of external regulation would highly depend on whether such formal punishments would substitute or complement existing informal managements (Lazzarini et al., 2004). Many cases have shown that externally imposed rules can replace existing arrangements, and hence, "crowd out" the established social norms (Cardenas et al., 2000). Our case shows 650 that the decision when to step in for a regulator is complex as it depends not only on whether social norms can be preserved, but also how far from the first-best outcome the current arrangement is. An erosion of social norms is less costly if collectively enforced resource level is very low. So there is probably an optimal point of intervention, which is clearly below the optimal stock level, but also higher than the open access level. This ${ }_{655}$ could be an exciting path for further theoretical, and also experimental studies. 


\section{References}

Agnew, D. J., Pearce, J., Pramod, G., Peatman, T., Watson, R., Beddington, J. R., and Pitcher, T. J. (2009). Estimating the worldwide extent of illegal fishing. PLoS ONE, $4(2): \mathrm{e} 4570$.

Allison, E. H. and Ellis, F. (2001). The livelihoods approach and management of small- 660 scale fisheries. Marine policy, 25(5):377-388.

Baland, J.-M. and Platteau, J.-P. (1996). Halting degradation of natural resources: is there a role for rural communities? Food \& Agriculture Org.

Becker, G. S. (1968). Crime and punishment: An economic approach. Journal of Political Economy, 76(2):169-217.

Biggs, R., Carpenter, S. R., and Brock, W. A. (2009). Turning back from the brink: detecting an impending regime shift in time to avert it. Proceedings of the National Academy of Sciences of the United States of America, 106(3):826-831. 19124774[pmid].

Biggs, R., Schlüter, M., Biggs, D., Bohensky, E. L., BurnSilver, S., Cundill, G., Dakos, V., Daw, T. M., Evans, L. S., Kotschy, K., Leitch, A. M., Meek, C., Quinlan, A., 670 Raudsepp-Hearne, C., Robards, M. D., Schoon, M. L., Schultz, L., and West, P. C. (2012). Toward principles for enhancing the resilience of ecosystem services. Annu. Rev. Environ. Resour., 37(1):421-448.

Boyce, J. R. (1995). Optimal capital accumulation in a fishery: A nonlinear irreversible investment model. Journal of Environmental Economics and Management, 28(3):324- 675 339 .

Bulte, E. H. and Horan, R. D. (2010). Identities in the Commons: The Dynamics of Norms and Social Capital. The BE Journal of Economic Analysis \& Policy, 10(1):Art.13.

Cardenas, J. C., Stranlund, J., and Willis, C. (2000). Local environmental control and institutional crowding-out. World Development, 28(10):1719 - 1733.

Clark, C. (2006). The Worldwide Crisis in Fisheries: Economic Models and Human Behavior. Cambridge University Press, first edition.

Clark, C., Clarke, F., and Munro, G. (1979). The optimal exploitation of renewable resource stocks: Problems of irreversible investments. Econometrica, 47(1):25-47.

Clark, C. W. (1990). Mathematical bioeconomics: the optimal management of renewable 685 resources. Wiley, second edition.

Copeland, B. R. and Taylor, M. S. (2009). Trade, tragedy, and the commons. American Economic Review, 99(3):725-49.

Costello, C., Ovando, D., Clavelle, T., Strauss, C. K., Hilborn, R., Melnychuk, M. C., Branch, T. A., Gaines, S. D., Szuwalski, C. S., Cabral, R. B., Rader, D. N., and Leland, 690 A. (2016). Global fishery prospects under contrasting management regimes. Proceedings of the National Academy of Sciences, 113(18):5125-5129.

Crépin, A. S. (2007). Using fast and slow processes to manage resources with thresholds. Environmental and Resource Economics, 36(2):191-213.

Crépin, A.-S., Nörberg, J., and Mäler, K.-G. (2011). Coupled economic-ecological systems 695 with slow and fast dynamics - modelling and analysis method. Ecological Economics, 70(8):1448-1458. 
Dixit, A. (1992). Investment and hysteresis. The Journal of Economic Perspectives, 6(1):107-132.

700 Eigaard, O. R., Marchal, P., Gislason, H., and Rijnsdorp, A. D. (2014). Technological development and fisheries management. Reviews in Fisheries Science and Aquaculture, $22(2): 156-174$.

Finus, M. and Maus, S. (2008). Modesty may pay! Journal of Public Economic Theory, $10(5): 801-826$.

705 Gallic, B. L. and Cox, A. (2006). An economic analysis of illegal, unreported and unregulated (IUU) fishing: Key drivers and possible solutions. Marine Policy, 30(6):689 695.

Gordon, S. (1954). The economic theory of a common-property resource: The fishery. Journal of Political Economy, 62(2):124-142.

710 Gutierrez, N. L., Hilborn, R., and Defeo, O. (2011). Leadership, social capital and incentives promote successful fisheries. Nature, 470(7334):386-389.

Hilborn, R., Branch, T. A., Ernst, B., Magnusson, A., Minte-Vera, C. V., Scheuerell, M. D., and Valero, J. L. (2003). State of the world's fisheries. Annual Review of Environment and Resources, 28(1):359-399.

715 Huang, L. and Smith, M. D. (2014). The dynamic efficiency costs of common-pool resource exploitation. American Economic Review, 104(12):4071-4103.

Janssen, M. A. (2015). A behavioral perspective on the governance of common resources. Current Opinion in Environmental Sustainability, 12:1-5.

Lazzarini, S. G., Miller, G. J., and Zenger, T. R. (2004). Order with some law: Complementarity versus substitution of formal and informal arrangements. Journal of Law, Economics, and Organization, 20(2):261-298.

Lubchenco, J., Cerny-Chipman, E. B., Reimer, J. N., and Levin, S. A. (2016). The right incentives enable ocean sustainability successes and provide hope for the future. Proceedings of the National Academy of Sciences, 113(51):14507-14514.

725 Maunder, M. N., Sibert, J. R., Fonteneau, A., Hampton, J., Kleiber, P., and Harley, S. J. (2006). Interpreting catch per unit effort data to assess the status of individual stocks and communities. ICES Journal of Marine Science: Journal du Conseil, 63(8):13731385 .

McKelvey, R. (1985). Decentralized regulation of a common property renewable resource industry with irreversible investment. Journal of Environmental Economics and Management, 12(4):287 - 307.

Melnychuk, M. C., Peterson, E., Elliott, M., and Hilborn, R. (2017). Fisheries management impacts on target species status. Proceedings of the National Academy of Sciences, 114:178-183.

735 Mirza, M. U., Richter, A., van Nes, E. H., and Scheffer, M. (2019). Technology driven inequality leads to poverty and resource depletion. Ecological Economics, 160:215 - 226.

Noailly, J., van den Bergh, J., and Withagen, C. A. (2003). Evolution of harvesting strategies: replicator and resource dynamics. Journal of Evolutionary Economics, 13(2):183200. 
Noailly, J., Withagen, C. A., and van den Bergh, J. (2007). Spatial Evolution of Social 740 Norms in a Common-Pool Resource Game. Environmental and Resource Economics, 36(1):113-141.

Nøstbakken, L., Thébaud, O., and Sørensen, L.-C. (2011). Investment behaviour and capacity adjustment in fisheries: a survey of the literature. Marine Resource Economics, 26(2):95-117.

Nyborg, K., Anderies, J. M., Dannenberg, A., Lindahl, T., Schill, C., Schlüter, M., Adger, W. N., Arrow, K. J., Barrett, S., Carpenter, S., Chapin, F. S., Crépin, A.-S., Daily, G., Ehrlich, P., Folke, C., Jager, W., Kautsky, N., Levin, S. A., Madsen, O. J., Polasky, S., Scheffer, M., Walker, B., Weber, E. U., Wilen, J., Xepapadeas, A., and de Zeeuw, A. (2016). Social norms as solutions. Science, 354(6308):42.

Ostrom, E. (1990). Governing the Commons: The Evolution of Institutions for Collective Action. Cambridge University Press.

Ostrom, E. (2009). A general framework for analyzing sustainability of social-ecological systems. Science, 325:419-422.

Richter, A. and Dakos, V. (2015). Profit fluctuations signal eroding resilience of natural 755 resources. Ecological Economics, 117:12-21.

Richter, A., Eikeset, A. M., van Soest, D., Diekert, F. K., and Stenseth, N. C. (2018). Optimal management under institutional constraints: Determining a total allowable catch for different fleet segments in the northeast arctic cod fishery. Environmental and Resource Economics, 69(4):811-835.

Richter, A. and Grasman, J. (2013). The transmission of sustainable harvesting norms when agents are conditionally cooperative. Ecological Economics, 93(0):202-209.

Richter, A., van Soest, D., and Grasman, J. (2013). Contagious cooperation, temptation, and ecosystem collapse. Journal of Environmental Economics and Management, 66(1):141-158.

Rust, S., Jennings, S., and Yamazaki, S. (2016). Excess capacity and capital malleability in a fishery with myopic expectations. Marine Resource Economics, 31(1):63-81.

Seijo, J., Defeo, O., and Salas, S. (1998). Fisheries bioeconomics: Theory, modeling and management. Fisheries Technical Paper 368, FOA.

Sethi, R. and Somanathan, E. (1996). The evolution of social norms in common property 770 resource use. American Economic Review, 86(4):766-788.

Squires, D. and Vestergaard, N. (2013). Technical change in fisheries. Marine Policy, $42: 286-292$.

Tavoni, A., Schlueter, M., and Levin, S. (2012). The survival of the conformist: Social pressure and renewable resource management. Journal of Theoretical Biology, 299:152- 775 161.

Taylor, M. S. (2011). Buffalo Hunt: International Trade and the Virtual Extinction of the North American Bison. American Economic Review, 101(7):3162-3195.

Taylor, P. D. and Jonker, L. B. (1978). Evolutionarily stable strategies and game dynamics. Mathematical biosciences, 40(2):145.

Varian, H. R. (1992). Microeconomic analysis. Norton \& Company. 
Villasante, S. and Sumaila, U. R. (2010). Estimating the effects of technological efficiency on the european fishing fleet. Marine Policy, 34(3):720 - 722 .

Vollan, B. and Ostrom, E. (2010). Cooperation and the commons. Science, 330(6006):923785 924.

Walker, B. H., Carpenter, S. R., Rockstrom, J., Crépin, A.-S., and Peterson, G. D. (2012). Drivers, "slow" variables, "fast" variables, shocks, and resilience. Ecology and Society, $17(3)$.

Whitmarsh, D. (1990). Technological change and marine fisheries development. Marine Policy, 14(1):15-22.

Worm, B., Hilborn, R., Baum, J. K., Branch, T. A., Collie, J. S., Costello, C., Fogarty, M. J., Fulton, E. A., Hutchings, J. A., Jennings, S., Jensen, O. P., Lotze, H. K., Mace, P. M., McClanahan, T. R., Minto, C., Palumbi, S. R., Parma, A. M., Ricard, D., Rosenberg, A. A., Watson, R., and Zeller, D. (2009). Rebuilding global fisheries. Science, 325(5940):578-585.

Yletyinen, J., Hentati-Sundberg, J., Blenckner, T., and Bodin, 2018). Fishing strategy diversification and fishers' ecological dependency. Ecology and Society, 23(3)(3):28. 